\title{
Met Daily NURSE ADL stimuleren
}

Citation for published version (APA):

Zwakhalen, S., Bleijlevens, M., Meijers, J., den Ouden, M., \& Hamers, J. (2019). Met Daily NURSE ADL stimuleren. TvZ - Verpleegkunde in praktijk en wetenschap, 129(5), 36-39. https://doi.org/10.1007/s41184019-0101-6

Document status and date:

Published: 01/01/2019

DOI:

10.1007/s41184-019-0101-6

Document Version:

Publisher's PDF, also known as Version of record

Document license:
Taverne

\section{Please check the document version of this publication:}

- A submitted manuscript is the version of the article upon submission and before peer-review. There can be important differences between the submitted version and the official published version of record.

People interested in the research are advised to contact the author for the final version of the publication, or visit the DOI to the publisher's website.

- The final author version and the galley proof are versions of the publication after peer review.

- The final published version features the final layout of the paper including the volume, issue and page numbers.

Link to publication

\footnotetext{
General rights Owners
rights.

- You may freely distribute the URL identifying the publication in the public portal. please follow below link for the End User Agreement:

www.umlib.nl/taverne-license

Take down policy

If you believe that this document breaches copyright please contact us at:

repository@maastrichtuniversity.nl

providing details and we will investigate your claim.
}

Copyright and moral rights for the publications made accessible in the public portal are retained by the authors and/or other copyright owners and it is a condition of accessing publications that users recognise and abide by the legal requirements associated with these

- Users may download and print one copy of any publication from the public portal for the purpose of private study or research.

- You may not further distribute the material or use it for any profit-making activity or commercial gain

If the publication is distributed under the terms of Article $25 \mathrm{fa}$ of the Dutch Copyright Act, indicated by the "Taverne" license above, 


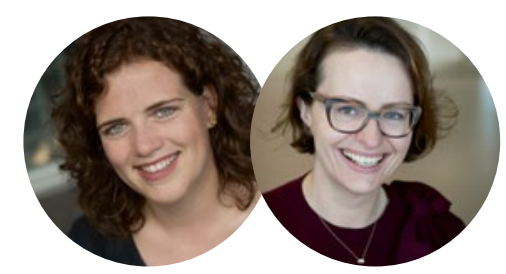

\section{REDACTIONEEL}

ANNE ESKES \& CATHARINA VAN OOSTVEEN

Hoofdredactie Onderzoek

\section{Choosing wisely}

Het is bekend dat het implementeren van wetenschappelijke kennis in de zorg een grote uitdaging is. Waar we voorheen vooral de focus legden op het implementeren van nieuwe evidence-based-interventies in de praktijk, komt er nu ook steeds meer aandacht voor het de-implementeren van ineffectieve interventies. Deze herkenning heeft ertoe geleid dat in 2012 de internationale campagne 'Choosing Wisely' gestart is. Deze campagne richt zich op het stimuleren van een dialoog tussen artsen en patiënten en heeft inmiddels ook de weg naar de verpleegkundige zorg gevonden. Om deze dialoog te stimuleren zijn er speciale 'do not do'-lijsten om zo verspilling door onnodige medische tests, behandelingen en procedures in de zorg te voorkomen. Dat deze campagne ook succesvol is gebleken in Nederland blijkt wel uit de medische en verpleegkundige beter-laten-lijsten (1366 medische verrichtingen versus 66 verpleegkundige handelingen). Ondanks dat het makkelijk lijkt om handelingen achterwege te laten vanwege de hoge werkdruk en het tekort aan verpleegkundigen, is het toch niet zo eenvoudig. De beter-laten-lijsten kunnen dus slechts als tools gezien worden, waarvan we weten dat -net zoals de allang bestaande richtlijnen- de aanwezigheid hiervan niet direct leidt tot veranderingen in de zorg.

Voor het inzetten van de beter-laten-lijsten (oftewel het de-implementeren) moeten we nadenken of we nieuwe implementatietechnieken nodig hebben. Zijn succesvolle implementatoren ook succesvolle de-implementatoren? Op basis van Nederlands onderzoek door Van Bodegom e.a. (2017) lijkt dit niet het geval te zijn. Zoals Van Bodegom e.a. stellen is het van belang dat we inzicht krijgen in de benodigde eigenschappen van een succesvolle de-implementatiefactor alswel in welke factoren bijdragen aan het slagen van de de-implementatie (bijvoorbeeld of de-implementatie moeilijker is als er geen alternatief voorhanden is). Misschien wel een mooi thema voor een volgende TVZ? Want als we dit soort kennis hebben, kunnen we onnodige handelingen efficiënter de-implementeren en zo meer tijd vrij maken voor waardevolle efficiënte zorg!

\section{Met Daily NURSE ADL stimuleren}

\author{
TREFWOORDEN \\ $\rightarrow$ ADL \\ $\rightarrow$ DAlly NURSE \\ $\rightarrow$ Verpleeghuis \\ $\rightarrow$ Ouderen
}

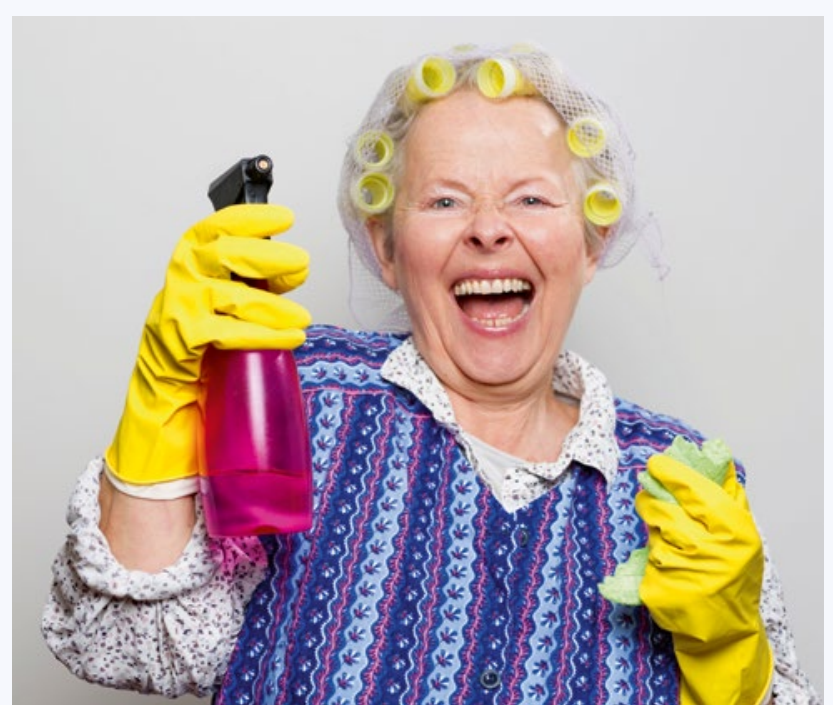



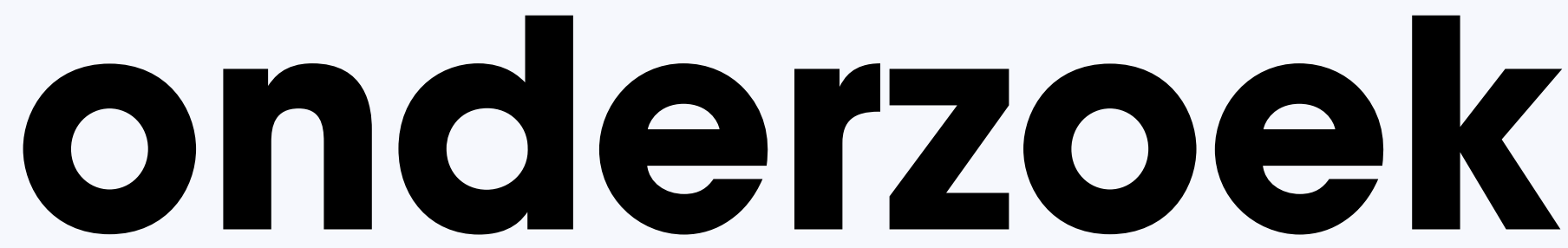

\begin{abstract}
'Bewegen is goed, meer bewegen
is beter' staat in de Nederlandse

Beweegrichtlijn. ${ }^{\top}$ Maar meer

bewegen is voor veel ouderen niet

zo vanzelfsprekend. Zeker niet als het

gaat om ouderen met dementie die in

een verpleeghuis wonen. De auteurs

ontwikkelden een interventie om ADL bij

deze ouderen te stimuleren.
\end{abstract}

\section{auteurs \\ SANDRA \\ ZWAKHALEN \\ hoogleraar \\ Verplegingswetenschap \\ MICHEL \\ BLEIJLEVENS \\ senior onderzoeker \\ JUDITH MEIJERS \\ senior onderzoeker \\ MIRRE DEN \\ OUDEN \\ onderzoeker \\ JAN HAMERS \\ hoogleraar \\ Ouderenzorg}

Allen werkzaam aan de vakgroep Health

Services Research, Universiteit Maastricht

\section{(a)}

CORRESPONDENTIE

SANDRA ZWAKHALEN

S.ZWAKHALEN@

MAASTRICHTUNIVERSITY.NL
Door actief te blijven in dagelijkse activiteiten, blijft het dagelijks functioneren en de conditie van ouderen in verpleeghuizen zo lang mogelijk behouden. Bovendien heeft het langer actief blijven een positieve invloed op de ervaren kwaliteit van leven.

Om zicht te krijgen op de ADL-activiteiten van verpleeghuisbewoners observeerden we op psychogeriatrische (PG) afdelingen in 7 Nederlandse verpleeghuizen 3282 keer. We inventariseerden wat de bewoners exact deden en wat de rol van verpleegkundigen en verzorgenden was bij deze activiteiten. De observatoren, die veelal verpleegkundigen waren van de betrokken zorgorganisaties, observeerden vaak inactiviteiten zoals slapen, niets doen of TV kijken. ${ }^{2,3}$ In bijna driekwart van de observaties werd dit waargenomen. Huishoudelijke activiteiten zoals tafel dekken, brood smeren en planten water geven, werden zelden tot nooit (4\%) geobserveerd. De verpleegkundige observatoren merkten ook op dat veel activiteiten, volgens hen, onnodig werden overgenomen door verplegend personeel en dat de restcapaciteit van bewoners niet optimaal werd benut en gestimuleerd.
Verpleegkundigen en verzorgenden spelen bij het stimuleren van ADL een sleutelrol. Door hun dagelijkse betrokkenheid kunnen zij deze activiteiten en zelfredzaamheid van bewoners als geen ander stimuleren. Zij kunnen bewoners stimuleren om bijvoorbeeld hun eigen brood te smeren, zelf koffie of thee in te schenken, of te helpen bij het dekken van de tafel.

\section{DOELSTELLING ONDERZOEK}

Om de grote mate van inactiviteit te verkleinen zouden verpleeghuisbewoners door verpleegkundigen en verzorgenden meer gestimuleerd moeten worden in dagelijkse activiteiten (ADL en met name Huishoudelijke activiteiten van het Dagelijkse Leven-HDL). In navolging van deze constatering werd er op basis van observaties, literatuur en werkgroepen, samen met de zorgverleners (o.a. verpleegkundigen, verzorgenden, fysiotherapeuten, ergotherapeuten) een interventie ontwikkeld voor verpleegkundigen en verzorgenden om dagelijkse activiteiten en zelfredzaamheid van verpleeghuisbewoners te stimuleren.

Deze interventie heet DAIly NURSE, een acroniem voor 'Daily Activities and Independence by NURsing Staff Encouragement'. ${ }^{4}$ De doelstelling van het onderzoek was de toepasbaarheid van DAIly Nurse te evalueren.

\section{OPZET VAN HET ONDERZOEK}

\section{Setting}

Voor deelname aan de studie werden psychogeriatrische verpleeghuisafdelingen van twee verpleeghuizen binnen de Academische Werkplaats Ouderenzorg Zuid-Limburg (AWO-ZL) bena- 
TABEL 1 VARIANTEN IN TOEPASSING VAN DAILY NURSE

\begin{tabular}{l|l|l}
\hline Educatie /workshops door & \multicolumn{1}{|c|}{$\begin{array}{c}\text { Verpleeghuis A, kleinschalige } \\
\text { afdelingen }\end{array}$} & \multicolumn{1}{|c}{$\begin{array}{c}\text { Verpleeghuis B, reguliere } \\
\text { afdeling }\end{array}$} \\
\hline Deelnemers workshop & $\begin{array}{l}\text { Aandachtsfunctionarissen van de } \\
\text { afdeling }\end{array}$ & $\begin{array}{l}\text { Gespecialiseerd verpleegkundige } \\
\text { met fysiotherapeut en ergothera- } \\
\text { peut }\end{array}$ \\
\hline Strategie voor bewustwording & Observaties & $\begin{array}{l}\text { Observaties en video-observaties } \\
\text { tijdens ontbijtmoment }\end{array}$ \\
\hline Tijd tussen workshops & $1.5-2$ weken & 4 weken \\
\hline Tijdstip Informatiebijeenkomst & Na workshop & Voor workshop \\
\hline & &
\end{tabular}

derd voor deelname. De AWO-ZL is een structurele samenwerking tussen zeven zorgorganisaties voor langdurige zorg en vier kennisinstellingen (twee mbo, hbo en universiteit).

Zie: www.academischewerkplaatsouderenzorg.nl.

\section{Doelgroep}

Aan de verpleegkundigen en verzorgenden van de deelnemende psycho- geriatrische verpleeghuisafdelingen werd gevraagd om deel te nemen aan het onderzoek. Daarbij werden geen specifieke inclusiecriteria gehanteerd.

\section{INTERVENTIE DAILY NURSE}

DAIly NURSE bestaat uit drie componenten, namelijk beleid, educatie en coaching. In de visie en het beleid van de organisatie wordt benadrukt dat dagelijkse activiteiten en zelfredzaamheid van verpleeghuisbewoners door alle professionals gestimuleerd worden.

Het in het beleid opnemen van de zorgaanpak zorgt ervoor dat DAIly NURSE gefaciliteerd wordt door het management, dat wil zeggen dat verpleegkundigen en verzorgenden ondersteuning krijgen bij het stimuleren van activiteiten en zelfredzaamheid van bewoners, onder andere door coaching en educatie.

De educatie bestaat uit drie workshops gericht op verpleegkundigen en verzorgenden. De workshops hebben als doel om de deelnemers bewust te maken van het belang van bewegen en hun rol bij de activiteiten en zelfredzaamheid van bewoners. Ook biedt de workshop handvatten om bewoners te stimuleren.

Coaching gebeurt door twee type coaches: de gespecialiseerd verpleegkundige en de aandachtsfunctionaris op de afdeling. Zij coachen collega's, vrijwilligers en mantelzorgers onder andere door het verzorgen van de workshops, het verspreiden van informatie of het geven van feedback op het stimuleren van activiteiten.

In deze studie werd op vraag van de deelnemende organisaties twee varianten van de interventie getest, afgestemd op de mogelijkheden en voorkeuren van de deelnemende organisaties. Daarbij was de voorwaarde dat de drie componenten onaangetast blijven en zouden worden geïmplementeerd. De twee varianten zijn in onderstaande tabel toegelicht.

\section{METEN TOEPASBAARHEID}

De toepasbaarheid van DAIly NURSE werd gemeten met behulp van zowel kwantitatieve als kwalitatieve metingen. Vragenlijsten, presentielijsten, notities van de onderzoeker en een focusgroepinterview met acht medewerkers aan het eind van de studie zijn daarvoor gebruikt.

Aan de hand van de gegevens werd nagegaan in welke mate de interventie geïmplementeerd en uitgevoerd werd zoals gepland, hoeveel medewerkers er zijn bereikt, hoe tevreden de medewerkers zijn met de interventie en welke barrières ze hebben ervaren. ${ }^{5}$

\section{RESULTATEN}

De studie is uitgevoerd binnen zes psychogeriatrische verpleeghuisafdelingen van twee verpleeghuizen. In totaal namen in verpleeghuis $A$ zes en in verpleeghuis B zeven zorgverleners deel. De aanwezigheid bij de workshops was hoog (gemiddeld 82\%). De deelnemers waren tevreden met de workshops (gemiddelde score $9 / 10$ punten).

Uit de studie naar de toepasbaarheid van de interventie kwam naar voren dat de interventie toepasbaar is in de dagelijkse zorgpraktijk. Verpleegkundigen en verzorgenden waren tevreden met de interventie en gaven aan dat DAIly NURSE kan helpen om dagelijkse activiteiten en zelfredzaamheid van bewoners te stimuleren.

Uit de haalbaarheidsstudie blijkt dat op beide afdelingen alle drie de componenten van DAIly NURSE (beleid, educatie en coaching) zijn geïmplementeerd. Zoals beoogd hebben beide organisaties de aanpak op een andere manier vorm gegeven (zie tabel 1). Dit testen van de varianten heeft veel waardevolle informatie opgeleverd voor het vervolg van de studie.

\section{VERVOLG}

De deelnemers in verpleeghuis $\mathrm{B}$ rapporteerden unaniem dat de video-observaties waarbij binnen het team op elkaars gedrag werd gereflecteerd een enorme meerwaarde hadden. Volgens de deelnemers was dit een zeer krachtige stimulans om bewustwording te creëren over hoe de verpleegkundigen en verzorgenden op de afdeling beweging stimuleren. Van observeren kun je dus leren.

Op basis van een focusgroep na afloop van de implementatie adviseerden deelnemers om de interventie te richten op een specifieke activiteit, te weten het ontbijtmoment. Een moment dat veel mogelijkheden biedt voor het stimuleren van activiteiten en dat voor iedere verpleeghuisbewoner dagelijks optreedt. 
Daarnaast gaven de deelnemers aan dat om voldoende draagvlak te creëren, bij voorkeur alle verpleegkundigen en verzorgenden van de afdeling zouden moeten worden betrokken in de workshops en niet enkel de aandachtsfunctionarissen van de afdeling. Ook werd gewezen op het belang van het organiseren van informatiebijeenkomsten voor familieleden voor de start van de interventie. Deze bevindingen werden als aanbevelingen meegenomen in het vervolg waarbij de interventie werd aangepast en geëvalueerd.

\section{NOOT}

1. Dit artikel is gebaseerd op het artikel: Den Ouden M, Zwakhalen SMG, Meijers JMM, e.a. Feasibility of DAlly NURSE: A nursing intervention to change nursing staff behaviour towards encouraging residents' daily activities and independence in the nursing home. J Clin Nurs. 2019;28(5-6):801-813. 2. Link naar factsheet: https://hsr.mumc.maastrichtuniversity.nl/sites/intranet. mumc.maastrichtuniversity.n//files/awo/public_news_ events/factsheet_mirre_den_ouden.pdf.Den Ouden, M. (2018). Every steps counts: daily activities of nursing home residents and the role of nursing staff. Maastricht: Datawyse / Universitaire Pers Maastricht. Het proefschrift van Mirre den Ouden vindt $u$ op de website van de AWO-ZL via de link: https://cris.maastrichtuniversity.nl/ portal/en/publications/every-steps-counts (9e61a084-51 19-4d17-88e8-7380e844e781).html.

\section{REFERENTIES}

1. Gezondheidsraad. Beweegrichtlijnen 2017. Publicatienr, 2017/08. Den Haag: Gezondheidsraad.

2. Den Ouden M, Bleijlevens MHC, Meijers JMM, e.a. Daily (in)activities of nursing home residents in their wards: an observation study. Journal of American Medical Directors Association. 2015; 16:963-968.

3. Den Ouden M, Kuk NO, ZwakhaIen SMG, e.a. The role of nursing staff in the activities of daily living of nursing home residents. Geriatric

Nursing. 2016;38:225-230.

\section{Den Ouden M, Zwakhalen SMG,} Meijers JMM, e.a. Feasibility of DAlly NURSE: a nursing intervention to change nursing staff behavior towards encouraging residents' daily activities and independence in the nursing home. J Clin Nurs. 2019:28(5-6):801-813.

5. Saunders RP, Evans MH \&Joshi P. Developing a process-evaluation plan for assessing health promotion program implementation: a how-to guide. Health Promot Pract.

2005;6(2):134-147.

\section{Samenvatting}

$\rightarrow$ DAlly NURSE is toepasbaar in de dagelijkse zorgpraktijk en kan verpleegkundigen en verzorgenden helpen om dagelijkse activiteiten en zelfredzaamheid van bewoners in verpleeghuizen te stimuleren.

$\rightarrow$ Bewustwording door middel van video-observaties tijdens een specifiek moment (zoals het ontbijt) wordt door verpleegkundigen en verzorgenden als een krachtig instrument gezien. De kracht van de observaties is daarmee mogelijk een belangrijke component in het daadwerkelijk veranderen van het gedrag van de verpleging om activiteiten meer te stimuleren.

$\rightarrow$ De aanbevelingen op basis van het haalbaarheidsonderzoek hebben de geplande aanpak in belangrijke mate gewijzigd. In de aangepaste aanpak ligt onder andere meer nadruk op het ontbijtmoment en is er meer aandacht voor video-observaties om bewustwording te stimuleren. $\rightarrow$ De ontwikkeling van de interventie samen met de doelgroep bevordert de implementatie.

$\rightarrow$ Om de interventie in het verpleeghuis toe te passen is een handleiding ontwikkeld die beschikbaar is op de website van de Academische Werkplaats Ouderenzorg Zuid-Limburg (https://www.academischewerkplaatsouderenzorg.nl/sites/intranet. mumc.maastrichtuniversity.nl/files/ awo/Producten/handleiding_daily_ nurse.pdf ). 